\title{
Journal of Bioengineering and Technology Applied to Health: A New Journal of Health Institute of Technology - ITS/SENAI CIMATEC
}

\author{
Leone Peter Andrade* \\ Editor-in-Chief; Provost SENAI CIMATEC; Salvador, Bahia, Brazil
}

The Manufacturing and Technology Integrated Campi SENAI CIMATEC started the activities in March of 2002. CIMATEC is one of the most advanced campus for education, technology, and innovation of industry in Brazil. This is a private non-profit institution supported by the Federation Industry of Bahia that was created to upgrade the"National Technical Learning for Industries Support". Recently, CIMATEC became a university campus with 33 engineering and computer science technological areas. In the present time, SENAI is supported by a staff of over 650 members to support the activities of professional and higher education, and a Technology Center, all encompassed in the same building structure.

SENAI CIMATEC School of Engineering initiated operations in 2004, and currently offers nine Undergraduate degrees courses in Engineering, and a series of Graduate programs, including lato sensu (specializations and MBAs) and stricto sensu (Master's and Doctoral degrees). In 2008, the Industrial Management and Technology (GETEC) and the Computational Modeling and Industrial Technology (MCTI) Master's Programs were inaugurated. MCTI incorporated a Doctorate in 2010, and, GETEC also opened a Doctorate Program in 2016.

SENAI CIMATEC prides on delivering highly qualified professionals to the several industrial sectors, supporting innovation and problem-solution, having earned the recognition

Received on 10 October 2018; revised 16 October 2018.

Address for correspondence: Dr. Leone Peter Andrade. This editoria was used in the launch of the JBTH in October 2018 (Special Issue). Avenida Orlando Gomes, 1845, Piatã. Zip Code: 41.650-010, Salvador, Bahia, Brazil. Phone (5571) 3879-8401. E-mail: leone@fieb.org.br.

J Bioeng. Biotech. Appl. Health

2019;1(1):1-2.

(C) 2019 by SENAI CIMATEC. All rights reserved. of Brazilian Ministry of Education as the top Engineering School in the North/Northeast Regions of Brazil in the last five years, and one of the most important institutions in innovation and knowledge in the country.

Even though CIMATEC activities are carried on in a decade, it is already recognized as one of the main Science and Technology Institutions of the country. The National Confederation of Industry of Brazil (CNI) has acknowledged publicly that SENAI CIMATEC is a reference in the implementation of the network of SENAI Innovation Institutes (ISI) and SENAI Technology Institutes (IST). ISIs are strong allies of the Brazilian industry in the development of products, processes and applied research. In our campus, there are three ISIs and six ISTs installed since 2014: the ISIs in Automation, Metal Forming, and Material Unions and Logistics, and the ISTs in Civil Construction, Chemistry, Electrical and Electronics, Food Technologies, Electromechanical, Environment, and Health.

SENAI CIMATEC runs projects of high national and international impact to support companies from different regions of Brazil with a strong performance in Research, Development, and Innovation (R\&D\&I). Although, it maintains a network of partners that include prominent universities and organizations from all over the world in the field of Software and Supercomputing; Mobility and Infrastructure; Metrology and Development of New Products and Materials; Robotics and Automated Systems; Energy and Sustainability; Advanced Manufacturing; Micro and Small Enterprises (MSE), Biotechnology, and Health.

In this scenario, SENAI CIMATEC created the Health Institute of Technology (ITS) in 2017 under the leadership of a national and 
international recognized scientist medical, Roberto Badaro, MD, PhD., to organizes the interfaces of the existing engineering technology of CIMATEC, to support the health industrial and economic complex in the development of drugs, medicines, equipment, and materials that are strategic for the public health system of Brazil (Brazilian Unified Health System - SUS). For that purpose, the Institute is working on research, development, innovation, regulation, publications, education and management of economic and welfare data. The Health Institute of Technology will develop cutting-edge technology to meet the demands of research, development, and innovation (R\&D\&I) projects in the area of Healthcare, Chemical and Biotechnology and Devices Applied to Health, which includes:

\section{Chemical and Biotechnology based Industry}

- Test for quality control of Generic medications;

- Development of analytical techniques applied to the analysis of active substances in pharmaceutic, cosmetic and phytotherapeutic formulations;

- Development of monoclonal antibodies, as diagnostic or therapeutic agents;

Development of recombinant proteins;

Development of chemically synthesized drugs;

Development of adjuvants;

Development of new Active Pharmaceutical Inputs (IFAs).

\section{Equipment and Materials for Health Use}

- Development of electromedical equipment;

- Assistive technology development;

- New materials applied to implants;

- Integrated systems (software, microelectronics, and embedded electronics);

- Data management software (Big Data and Telemedicine);

- The E-Health;

- The augmented reality and virtual with medical applications (IoT);

- Robotic surgery;

- Development of diagnostic kits.
Quality, Regulation, and Management Incorporation of technologies in SUS; Economic regulation: the possibility of tax alteration; attracting foreign companies to Brazil from government incentives; certification and test of products;

- Management of economic data, epidemiological, regulatory, and development of new technologies (clinical trials).

The biotechnology and innovation market grows exponentially in Latin America. With the new purpose of incorporating 4.0 concept into the area of healthcare, an enormous number of new scientific information in technologies applied to health are available. A new journal devoted to publishing this information would help to foster collaborations in these technologies that can be applied to the development of health tools among scientists in the world.

In this sense, ITS/SENAI CIMATEC created The Journal of Bioengineering and Technology Applied to Health (JBTH) in order to open the opportunity to speed these collaborations. JBTH is a peer-review open access and multidisciplinary Journal with the aim to develop a platform for innovative researchers and scientists to explore the advanced and latest research developments in the field of Biomedical Engineering and related disciplines that are applied to the development of new tools for diagnostics and treatment in the area of healthcare.

JBTH will publish articles related to the most recent advancement discoveries and applications in the field of bioengineering, biotechnologies, Big Data, nanotechnologies, molecular engineering, biochips, medical electronics, medical devices and instrument guided surgeries, biomechanics, clinical engineering, genetic engineering, photonics, new therapeutic strategies including steam cell therapies, gene therapy, new molecular biology discoveries and any scientific reliable information on advanced and very latest research topics. 